\title{
Food group intakes in a representative sample of adults aged 18-64 years in Ireland
}

\author{
C. Cummins ${ }^{1}$, S. Bannon ${ }^{1}$, J. Walton ${ }^{1}$, B. McNulty ${ }^{2}$, A. Nugent ${ }^{2}$, M. Gibney ${ }^{2}$ and A. Flynn ${ }^{1}$ \\ Irish Universities Nutrition Alliance (IUNA) at: ${ }^{1}$ School of Food and Nutritional Sciences, University College Cork, \\ Cork, Republic of Ireland and ${ }^{2}$ UCD Institute of Food and Health, University College Dublin, Belfield, Dublin 4, \\ Republic of Ireland
}

The objective of this study was to examine food group intakes (total population and consumers only) of adults aged 18-64 years ( $n$ 1274) in Ireland. Analysis was based on the National Adult Nutrition Survey (NANS), which was carried out to establish a database of habitual food and beverage consumption in a representative sample of adults in Ireland. A 4-d semi-weighed food record was used to collect food and beverage intakes.

\begin{tabular}{|c|c|c|c|c|c|}
\hline & \multicolumn{5}{|c|}{$18-64$ years $(n 1274)$} \\
\hline & \multicolumn{2}{|c|}{ Total population $(\mathrm{g} / \mathrm{d})$} & \multicolumn{3}{|c|}{ Consumers only $(\mathrm{g} / \mathrm{d})$} \\
\hline & Mean & SD & $\%$ & Mean & SD \\
\hline Breads & 115 & 63 & 98 & 117 & 61 \\
\hline White breads & 51 & 52 & 78 & 66 & 50 \\
\hline Brown/wholemeal breads & 52 & 54 & 73 & 71 & 51 \\
\hline Breakfast cereals & 57 & 78 & 74 & 77 & 81 \\
\hline Ready-to-eat breakfast cereals & 24 & 30 & 61 & 39 & 29 \\
\hline Other breakfast cereals (e.g. porridge) & 33 & 79 & 24 & 138 & 105 \\
\hline Dairy products & 259 & 202 & 98 & 263 & 201 \\
\hline Whole milk & 102 & 169 & 61 & 169 & 190 \\
\hline Low fat milk & 93 & 143 & 51 & 181 & 155 \\
\hline Potatoes & 120 & 86 & 93 & 128 & 83 \\
\hline Potatoes (e.g. boiled, baked and mashed) & 71 & 74 & 74 & 96 & 71 \\
\hline Chipped/fried/roasted potatoes & 43 & 51 & 65 & 66 & 49 \\
\hline Meat & 183 & 101 & 98 & 187 & 98 \\
\hline Fresh meat $(\mathrm{g})$ & 58 & 53 & 82 & 71 & 50 \\
\hline Processed meat $(\mathrm{g})$ & 61 & 55 & 90 & 68 & 54 \\
\hline Fruit and vegetables & 185 & 147 & 98 & 189 & 146 \\
\hline Vegetables & 94 & 70 & 96 & 98 & 69 \\
\hline Fruit & 91 & 110 & 70 & 131 & 111 \\
\hline Beverages & 1563 & 872 & 100 & 1565 & 870 \\
\hline Teas & 422 & 410 & 81 & 519 & 396 \\
\hline Coffees & 139 & 228 & 50 & 278 & 256 \\
\hline Carbonated beverages & 106 & 176 & 46 & 233 & 197 \\
\hline Non-diet carbonated beverages & 82 & 159 & 37 & 223 & 193 \\
\hline Diet carbonated beverages & 24 & 79 & 14 & 176 & 142 \\
\hline Biscuits, cakes and pastries & 30 & 35 & 76 & 39 & 36 \\
\hline
\end{tabular}

Potatoes, breads, meat and dairy products are staple foods in the diets of adults in Ireland, consumed by almost the whole population group. Breakfast cereals are also widely consumed in the population. Intakes of white and brown/wholemeal breads are similar, approximately 2 slices per day in consumers. Although fruit and vegetables were consumed by the majority of the population, there was low compliance $(9 \%)$ with the WHO recommendation of $400 \mathrm{~g} / \mathrm{d}^{(1)}$.

The project was funded by the Department of Agriculture, Fisheries and Food under the Food for Health Research Initiative.

1. WHO (2003) Diet, Nutrition and the Prevention of Chronic Disease. WHO Technical Report Series 916. Geneva: WHO. 